\title{
Are Family-Supportive Practices Strategic for Brazilian CEOs?
}

Letícia Maria Barbano (leticia@familytalks.org) - Researcher at Family Talks Corresponding author: Rua Sergipe, 475, Conj 110, Consolação. São Paulo - SP - Brazil. Natalia Castro (ㅁatalia.castro@ ise.org.br) - ISE Business School (São Paulo/Brazil) Pedro Hollanda (pedro.hollanda@mdh.gov.br) - Brazilian Ministry of Women, Family and Human Rights (Brasilia/Brazil)

Acknowledgements
“Associação de Desenvolvimento da Família" (ADEF) and ISE Business School for supporting this research

Declaration of Conflicting Interests The Authors declare that there is no conflict of interest

\begin{abstract}
:
Purpose: The goal of the present study was to investigate chief executives' intention and potential to create a family-supportive culture in the Brazilian context, further assessing the role of their aspirations in their employees' perceptions. Methodology: Two researchers conducted 60 minutes of online semi-structured interviews with CEOs of seven companies of different sizes (measured by the number of employees), economic sectors, and capital structure. To complement the data gathered from CEOs, we also conducted private and individual 30minute online interviews with three employees from each company. Findings: A total of four categories and 11 sub-categories emerged from the analysis of CEO interviews, and four categories and six sub-categories emerged from the analysis of employee interviews. Originality: The results suggest that family-supportive culture is promoted through behaviors that are consistent with the organization's core values, as well as through commitment of the agenda and resources of the company's leadership team.
\end{abstract}

KEYWORDS: family-supportive workplaces, corporate family responsibility, ethical leadership, authentic leadership, family-supportive supervisor behavior, chief executive officer 


\section{Introduction}

Family-supportive companies — also called "family-friendly" — are those that offer an organizational structure that allows workers to effectively balance the demands of work and family (Greenhaus and Allen, 2011). This issue has received attention, especially during the COVID-19 pandemic, during which the boundaries between work and home became blurred and people's private lives were noted as undissociated from their professional lives (Hjálmsdóttir and Bjarnadóttir, 2021; Vaziri et al., 2020).

In contrast, the pandemic context also increased awareness of companies' responsibilities to build on their internal and external missions. This was driven by focus on reducing the negative impact of the usage of natural resources and by the fact that companies are facing ongoing scrutiny by investors and society (Durand et al., 2019; Lagasio and Cucari, 2019; Welch et al., 2020; Yoon et al., 2018). Environmental, social and governance (ESG) pillars were translated into non-financial reporting metrics that claim the end of "shareholderism," to consolidate the emergence of the "stakeholderism" as an important subject on leading executives' agendas (Freeman, 1984; Lund, 2020; Parmar et al., 2010). This means a change in focus of the purpose of businesses from the exclusive importance of profits to importance given to all stakeholders involved in the success of a company, especially employees, who are considered the first business stakeholder (Freeman, 1984; Parmar et al., 2010).

Within a company's ecosystem, sustainable and ethical stakeholder management contributes to the companies' legitimacy and increases its likelihood of success (Welch et al., 2020; Yoon et al., 2018). Such stakeholders include employees, shareholders, suppliers, consumers, community, government, and competitors Success can be defined in terms of employees' outcomes and how society views the company, along with economic results, which can also be improved as a consequence of employees' engagement and well-being (Harter et al., 2002; Welch et al., 2020).

Employees' families are also part of this ecosystem, and family support could be considered an emergent characteristic of sustainable businesses (Lund, 2020; Rofcanin et al., 2018). As social beings, all humans are part of a family or community (Donati, 2003, 2014), and lived experiences can reverberate positively or negatively in other domains, such as in the professional domain (Sirgy and Lee, 2017). Thus, the family experience can remarkably impact 
employees' performance and outcomes, and hence, impact the organization (Greenhaus and Allen, 2011; Li et al., 2017; Sirgy and Lee, 2017).

Ethical and servant leadership can enhance employees' outcomes through increased engagement, motivation, and job and life satisfaction (Eva et al., 2019; Ko et al., 2017; Rofcanin et al., 2021; Zhang and Tu, 2016). Successful implementation of a family-supportive culture is strongly reliant on the behavior modeled by its leading executives (Eva et al., 2019; Gardner et al., 2011; Las Heras et al., 2015; Li et al., 2017). This is because leaders' concerns about employees' well-being can inspire and influence the entire organization (Eva et al., 2019; J et al., 2011; Ko et al., 2017; Li et al., 2017; Rofcanin et al., 2021).

Based on the central role of leaders, the main objective of this study was to investigate chief executives' intention and potential to create a family-supportive culture in the Brazilian context. Additionally, the study determined the strategies they use to demonstrate genuine awareness and supportive behaviors regarding conflicts and issues that arise when balancing companies' missions and collaborators' professional and personal lives.

\section{Methodology}

Two researchers conducted 60 minutes of online semi-structured interviews with CEOs of seven companies of different sizes (measured by the number of employees), economic sectors, and capital structure. Companies selected were organizations whose press reviews indicated alignment with family-supportive behaviors. Questions to the CEOs included, but were not limited to: "What does it mean for you to be family-supportive?" "How do family-supportive practices relate to your business model?" "What practices do you promote in organizations?" "How is family supportive?" and "What is your advice for other leaders who want to be family supportive?"

To complement the data gathered from CEOs, we also conducted private and individual 30minute online interviews with three employees from each company. We asked HR departments for a list with ten names of employees, and we blindly chose three from that list. Questions to the employees included, but were not limited to: "What support does the company provide you and your family?" "How do you evaluate this support?" "What can be improved?" "What do you like most about this company?" "What are the biggest challenges you face in balancing work and family responsibilities?" "What is the company's position regarding your professional growth versus the challenges of dedicating time to your family?" "Have you ever 
faced any kind of prejudice/limitation due to being a mother/father?' and 'How does this affect job satisfaction?"

Data collection took place between September 2020 and April 2021. All interviews with CEOs and employees were transcribed and analyzed following content analysis methodology (Bardin, 2007). This analysis is divided into three stages: 1) Pre-analysis, to organize and conduct the first material review; 2) Encoding, in which texts are read again and classified into themes that emerged from their content; and 3) Categorization, in which themes are grouped into categories, after which researchers may perform critical interpretation of the data. To mitigate bias in the analysis, the first researcher performed the content analysis, and a second researcher performed the same process and reclassified the material. Both researchers agreed on the final version.

\section{Results}

Seven companies participated in the study. They varied in the following characteristics: i) size (from 450 to over 23,800 employees); ii) sector (retail, logistics, agricultural devices, banking, consultancy, energy, and specialty [fragrances)); and iii) capital structure (government/family/privately owned and publicly traded companies).

Seven CEOs and 21 employees were interviewed. Employees had different job descriptions and hierarchy levels within each organization. The average time working for the company of employees was 15.4 years $(S D=9.6)$. Deeper characterization of the sample cannot be presented to protect identities, especially those of employees.

\section{CEOs' Categories}

A total of four categories and 11 sub-categories emerged from the analysis of interviews with CEOs. The categories represent a proposed grouping of the sub-categories found while analyzing the interviews. These categories exemplify the leadership strategies implemented to foster a family-supportive culture, showing the actual intention of leadership to be a role model. Table 1 summarizes these results. 
Table 01: Categories from CEOs' interviews' analysis.
Categories
Sub-categories

1. Voicing and

implementing ideas that

benefit employees and

surrounding communities
1.1. Promoting Community Education

Opportunities / Community

Improvements Around the Company

1.2. Support the Family as an extension of the employee in the company

1.3. Listen To Collaborator / Look At

Each One as Singular

1.4. Gender Equity / Inclusion Actions
2. Nourish non-hierarchical relationships
2.1. Foster collaborative

environment/work in teams
3. Grant autonomy to managers
3.1. Trust and Autonomy

3.2. Investment in training and mentoring / alignment with company culture
4. Seek positive role model behavior from senior leadership
4.1. Practices/Benefits as support for culture

\subsection{Internal Cohesion in Senior}

Management / Convincing of the high leadership of ideas and agendas 


\subsection{Leading roles as an example}

4.4. Engagement by purpose / Pride to belong

The first category, "the importance of voicing and implementing ideas that benefit employees and surrounding communities," encompassed quotes addressing the importance of dialog within the company, commitment of resources, and promotion of leadership buy-in on important matters for the company, beyond those related to business continuity. Concern with the local community was raised by several CEOs from different perspectives: through the promotion of education opportunities, life quality programs, housing, and violence prevention programs. The communities surrounding the company were viewed as important stakeholders; actions towards them could impact the families of employees by extension, and companies' future viability. The following quotes exemplify our findings:

"What does public education have to do with our company? It's got everything. If we don't help improve public education, tomorrow these people will be in the company working." (CEO 3)

"I've never seen a distinction between work life and family life. Work and family have not excluded spheres, everything is interconnected. If I'm not living a good time in my personal life, it impacts my work. If I'm professionally wrong, it impacts my personal life. The human being is an integral being. So, yes, the company has an obligation to look to the employee's family, both to take care of the people who are important to him, and to improve his performance in the company." (CEO 1)

"It is a great difficulty to reconcile the pressure for results that there is in all companies with this a little more human management, thinking about the moment of each one. These decisions are complex. We've had cases of people who received bad reviews and were going to be fired, but they brought the news: 'I'm going to have a baby'. I immediately said, 'We're not going to fire anymore. 
Let's take the bad performance'. What comes first? The person or the result? When it is a decision that will affect the life of a family, does the result or those people who are affected come first?" (CEO 5)

The second category, "nourish non-hierarchical relationships to facilitate dissemination of values and best practices," encompassed text that expressed active enforcement of equitable treatment for all people and hierarchies inside organizations, because everyone was seen as part of a team that equally contributed to a common goal: the success of the company.

"It doesn't matter what idea and who it came from. The important thing is to promote an environment that everyone has built a little, that everyone has collaborated, that everyone feels part of it. It generates engagement and makes people proud to work here." (CEO 7)

"That idea about "people doing whatever they want outside the work, but, inside here they should be good professionals" is not true anymore. As society goes more horizontal, non-hierarchical, people are becoming more equal and that incoherence between private and public life loses its logic. On the other hand, there is a culture saying that we have to be strong all the time. Hence, to support personal needs can be difficult to be accepted at the workplace. Those points could make leadership not accept being involved in work-family balance issues. However, nowadays there is pressure from society to paradigm shift. In the long run, companies cannot be only profits and results: we need to have a purpose besides this." (CEO 5)

The third category, "grant autonomy to managers," encompassed the CEOs' thoughts about the importance of granting discretionary autonomy to managers to accommodate individual needs. This is especially pertient for those with caregiving responsibilities and the need to balance work and family duties. The following quotes exemplify our findings:

"Especially with the home office, many questions how we know the person is really working. We rely on the work of the employees. If the person does not work, the result does not appear. Simple. But I assure you that for most people, granting autonomy and trust generates much greater productivity." (CEO 2) 
"We always invest in people and their families as part of our values and responsibility. Although we do not measure the impact this has had financially on our business over time, we have received several awards and we have excellent results, both from the point of view of promise and productivity, as well as in economic terms" (CEO 6)

The fourth category, "seeking positive role model behavior from senior leadership," encompassed the need for leaders themselves to follow the core values of the company so that the organization perceives these values as genuine. To put this into practice required internal agenda cohesion among senior management.

"When we decide to have a discussion, to defend a point, we need to have space on our agenda for that to happen. Also, the top management needs to be aligned and believing in the initiative because without their support, the initiative will not happen" (CEO 1)

"As the Americans say: walk the talk, set an example, do what you say, that's what transforms the company. I've been repeating this to the staff: nobody hears what we say, but everyone sees what we do. Observation is much more important than the discourse and written politics of the organization." (CEO 4)

\section{Employees' Categories}

A total of four categories and six sub-categories emerged from the analysis of employees' interviews. These categories exemplified the perceptions of workers of a family-supportive workplace. Table 2 summarizes these results. 
Table 02: Categories from employees' interviews' analysis.

Categories Sub-categories

1. Focus on gender equity 1.1. Gender equity

The company as part of their $\quad 2.1$. Support network
support network;

3. Perceived effort to promote 3.1. Less hierarchy, more horizontality cooperative and horizontal relationships within the organization 3.2 . Cooperative teams

4. Perceived individual care

4.1. Support to take care of personal and family matters.

4.2. Reduced/flexible working hours and telework

The first category, "perceived focus on gender equity, especially for those with family responsibilities," encompassed quotes emphasizing fostering gender equity in a more impactful way to support people with caregiving or family responsibilities. Gender inequality inside and outside the workplace occurs primarily because, in general, women devote more time than men to household and care tasks. The following quotes exemplify our findings:

"I've seen a lot of people promoted when they're eight months pregnant. Motherhood is seen as something natural here." (Employee 10)

"Today there are clearly many women who behave like men because they want to match them. The woman needs to be respected as a woman, 
whether or not she is a mother - no matter where she is or what she does [in charge]." (Employee 3)

The second category, "recognition of the company as part of their support network," was defined by speech expressing that an important characteristic of family-supportive companies is that they offer an inclusive workplace for all employees. This includes promoting a culture that sees the reconciliation of family commitments and professional tasks as natural.

"No one here judges you because you're away from a personal problem or going through a difficult time. I've happened to be pretty tired and asked if I'd like help if that was okay. I know I'm in an environment that if you need to just shout that five or ten people will show up." (Employee

The third category, "perceived effort to promote cooperative and horizontal relationships within the organization" represented characteristics common to organizations that pay greater attention to the family responsibilities of their employees: horizontality in professional relationships. When personalized attention is offered and space given to each employee to voice their individual perceptions and needs, the consequence is less command and control, leading to more cooperative professional relationships and a more inclusive organizational environment.

"Here you don't realize who the director is, who's the boss, there's no distinction, there's no different outfit - that 'thing' of a jacket, tie, you know? No, here everyone dresses with simplicity, everyone is treated well." (Employee 20)

"There is something interesting here: every new person who arrives, especially interns, receives individual support and accompaniment, as a 'cicerone' or 'godfather'. As much as the culture of the organization says that there is no hierarchy, who is new has not yet absorbed this and can have any doubts. So, this godfather will give support, ask questions, leave the environment more favorable for adaptation." (Employee 12)

"It is not common here to expose our positions, when we were promoted, how much we earn... Far from it, that's not our goal! We don't want to 
create hierarchical levels in the company. The idea is to work as a team." (Employee 2)

"A colleague had to take care of her father who had cancer and was being super difficult for her. When she signaled this, we called her to talk and said, 'Put your demands here on the table, let's redivide between the team internally, because I know you're going to stay longer at home with your father, helping, or in the hospital. So, let's redivide the tasks here'." (Employee 4)

The fourth category, "perceived individual care", explicitly included the importance of bearing singular needs from employees beyond the companies' policies or benefits offered. When there is conflict at work, this is negatively reflected in how the person interacts with the family. If there is conflict in the family, there is a negative reflection in the professional sphere. Providing support for employees to take care of personal demands represents a win-win, with clear benefits for the organization. Flexible arrangements can be a useful tool for balancing work and family obligations.

"The company has this benefit of the employee moving away to take care of their descending or ascending loved one. I used this only once because my daughter had to undergo surgery, I spent more than 15 days taking care of her. It didn't get in the way of anything, I stayed on the list to be promoted, it had no impact on vacation or salary." (Employee 15)

"If the person is absent, it is because he really needs to do it. My manager even says he needs to leave, he doesn't even have to ask. We warned the team not to make an appointment at that time. Everyone knows their own agenda and demands." (Employee 19)

"No one is productive 8 to 10 hours a day, 6 days a week. The reduction of the journey and flexible arrangements were excellent for us." (Employee 8) 


\section{Discussion}

The main objective of this study was to investigate chief executives intentions and strategies for creating a family-supportive culture in the Brazilian context. There were no perceived discrepancies between CEOs' interviews and employees' interviews, considering that the intention to create a family-supportive workplace was perceived as genuine by the employees. In our view, this link between categories suggests coherence of the companies' strategies. Although the links between CEO and employee categories can be interpreted from different perspectives, we propose a parallel between them, evidencing their complementary view:

\section{CEO Category: Voicing and implementing ideas that benefit employees and surrounding communities}

\section{Employee Category: The company as part of the employee support network}

Our analysis of this category from the CEO's interviews revealed the importance of creating a safe space to voice emerging needs, priorities, and concerns (Eva et al., 2019; Ko et al., 2017). This dialog facilitates awareness and enables issues to emerge and be properly addressed. If an issue is not raised to the leadership team, it is likely to remain unresolved, with no proper support or attention to how intrinsic or emblematic the issue is to the company's culture and strategy ( $\mathrm{J}$ et al., 2011; Waldman et al., 2006). This is in accordance with family-supportive supervisor behavior, as well as with the potential of an individual to thrive at work (Qing et al., 2021; Rofcanin et al., 2017; Russo et al., 2015). Certain issues demand a step of leadership awareness and education prior to establishing any new practice or procedure. After this stage, submitting possible solutions to other members of the leadership team, or even a specialized third party, converges the company to action. Finally, implementing these ideas commits the company to continuously challenge itself, with high expectations. It is important to note that the extension of practices to include benefits to surrounding communities is in accordance with integrative and ethical corporate social responsibility theories (Garriga and Melé, 2004). Such theories consider that businesses should integrate social demands as they depend on society for their continuity and growth. Further, that the relationship between business and society is embedded with ethical values that lead to a greater sense of belonging among employees is crucial to the existence of the business itself (Garriga and Melé, 2004; Lagasio and Cucari, 2019; Welch et al., 2020). 


\section{CEO Category: Nourish non-hierarchical relationships}

\section{Employee Category: Promote cooperative and horizontal relationships within the organization}

Non-hierarchical relationships can be nourished through the proximity and unity of a company's managers in how they disseminate its systems of beliefs, values, and best practices, rather than through the formalization of rules (Eva et al., 2019; J et al., 2011; Ko et al., 2017; Li et al., 2017; Rofcanin et al., 2017, 2021). Proactive, forward-looking, stresspreventing behavior is not the sole purview of supervisors, but can also be promoted by coworkers, consistent with the fact that employees can generate ideas and solutions of potential benefit to the whole group and organizational unit (McMullan et al., 2018; Norling and Chopik, 2020).

Although facilitated by the companies' formal organizational structure, this formal design does not limit the companies' ability to foster an environment that seeks these nonhierarchical relationships. Moreover, establishing non-hierarchical relationships depends primarily on how information flows within the company, the proper distribution of power and authority, coherent control systems, and the maintenance of a culture that allows questioning the status quo, co-creation of practices, and safe spaces for self-expression.

\section{CEO Category: Grant autonomy to managers}

\section{Employee Category: Perceived individual care}

These categories relate to developing a culture that fosters trust to accommodate individual needs. Grant managers' autonomy is expressed by both having the means and the power to propose changes to the company's modus operandi. Regarding this discretionary power, Daverth, Hyde, and Cassell (2016) found evidence that a manager might wish to offer support but perceive low discretion available to them to act accordingly. These findings are in accordance with i-deals theory, in which personalized win-win agreements are made between supervisors and employees to accommodate individual needs (Rousseau et al., 2006). This workplace characteristic creates a humanized atmosphere for employees and, as a result, they feel more engaged and aligned with the company's culture (Daverth et al., 2016; Hornung, 2018; Liao et al., 2016; Qing and Zhou, 2017; Rofcanin et al., 2018; Rothschild, 2000). 


\section{CEO Category: Seek positive role model behavior from senior leadership Employee Category: Focus on gender equity}

This finding emphasizes that organizational culture is essentially communicated to employees through senior leadership attitudes and decisions. This is in accordance with the theory of ethical leadership and authentic leadership, which emphasizes that role model behavior from top management has a positive effects at all levels of the organization (Gardner et al., 2011; J et al., 2011; Ko et al., 2017; Li et al., 2017). In addition, when lived core values consolidate organizational culture, this is perceived as genuine and coherent by employees and other stakeholders (Gardner et al., 2011; Shaubroeck et al., 2011). Work-family balance practices, truly modeled and enforced by leadership, can remove negative repercussions of employees engaging in such practices. This stigma often translates as a lack of commitment from employees, and hence blocks or prevents career advancement. In contrast, a company that promotes gender equity as intrinsic to the business (Li et al., 2017; Padavic et al., 2020) encourages available resources to be used by workers without fear of negative career consequences (Ko et al., 2017; Li et al., 2017).

\section{Conclusion}

Fostering a family-supportive workplace was prioritized by the Brazilian CEOs interviewed in the present research. This went beyond implementing family-supportive practices to actively engage the leadership team in creating a family-supportive culture. Such support materialized through behaviors consistent with the organization's core values and the people-related goals reflected in these values, as well as through the commitment of agenda and resources at the leadership team level of the company.

Practical implications of this study are that businesses interested in being aligned with a familysupportive culture should promote this through top management and senior leadership transformation, which should further be aligned with revised long-term values and tangible benefits offered.

In terms of its theoretical contribution, the present study adds to the leadership literature regarding the importance of investing in ethical and authentic leadership to promote a sustainable and family-supportive workplace. 
Limitations include the qualitative approach (instead of mixed-method research) and the limited number of employees interviewed. Future research could investigate the following topics: whether employees' positive perceptions and identification with companies' values emerge more consistently among companies whose CEO is spontaneously identified as an ethical leader, whether discretionary power to address individual needs is perceived as important to increase employees' engagement regardless of hierarchy or business model, and if family supportive and ethical leadership positively contribute to the company's longevity and financial returns.

\section{References}

Bardin, L. (2007), L'analyse de Contenu.

Daverth, G., Cassell, C. and Hyde, P. (2016), "The Subjectivity of Fairness: Managerial Discretion and Work-Life Balance", Gender, Work \& Organization, John Wiley \& Sons, Ltd, Vol. 23 No. 2, pp. 89-107.

Donati, P. (2003), Introduzione Alla Sociologia Relazionale, Vol. 5, FrancoAngeli.

Donati, P. (2014), Manuale Di Sociologia Della Famiglia, Gius. Laterza \& Figli Spa.

Durand, R., Paugam, L. and Stolowy, H. (2019), "Do investors actually value sustainability indices? Replication, development, and new evidence on CSR visibility", Strategic Management Journal, John Wiley \& Sons, Ltd, Vol. 40 No. 9, pp. 1471-1490.

Eva, N., Robin, M., Sendjaya, S., van Dierendonck, D. and Liden, R.C. (2019), "Servant Leadership: A systematic review and call for future research", The Leadership Quarterly, JAI, Vol. 30 No. 1, pp. 111-132.

Freeman, R.E. (1984), Strategic Management: A Stakeholder Approach, Pitman, Boston.

Gardner, W.L., Cogliser, C.C., Davis, K.M. and Dickens, M.P. (2011), “Authentic leadership: A review of the literature and research agenda", The Leadership Quarterly, JAI, Vol. 22 No. 6, pp. 1120-1145.

Garriga, E. and Melé, D. (2004), "Corporate Social Responsibility Theories: Mapping the Territory”, Journal of Business Ethics 2004 53:1, Springer, Vol. 53 No. 1, pp. 51-71. 
Greenhaus, J.H. and Allen, T.D. (2011), "Work-family balance: A review and extension of the literature.", Handbook of Occupational Health Psychology (2nd Ed.)., No. August, pp. $165-183$.

Harter, J.K., Schmidt, F.L. and Hayes, T.L. (2002), "Business-unit-level relationship between employee satisfaction, employee engagement, and business outcomes: A meta-analysis", Journal of Applied Psychology, American Psychological Association Inc., Vol. 87 No. 2, pp. 268-279.

Las Heras, M., Bosch, M.J. and Raes, A.M.L. (2015), "Sequential mediation among family friendly culture and outcomes", Journal of Business Research, Elsevier, Vol. 68 No. 11, pp. 2366-2373.

Hjálmsdóttir, A. and Bjarnadóttir, V.S. (2021), "'I have turned into a foreman here at home’: Families and work-life balance in times of COVID-19 in a gender equality paradise", Gender, Work \& Organization, John Wiley \& Sons, Ltd, Vol. 28 No. 1, pp. 268-283.

Hornung, S. (2018), "Idiosyncratic Deals at Work: A Conceptual and Empirical Review", Springer, Cham, pp. 265-281.

J, S., SS, L. and AC, P. (2011), "Cognition-based and affect-based trust as mediators of leader behavior influences on team performance", The Journal of Applied Psychology, J Appl Psychol, Vol. 96 No. 4, pp. 863-871.

Ko, C., Ma, J., Bartnik, R., Haney, M.H. and Kang, M. (2017), "Ethical Leadership: An Integrative Review and Future Research Agenda”, Https://Doi.Org/10.1080/10508422.2017.1318069, Routledge, Vol. 28 No. 2, pp. 104132.

Lagasio, V. and Cucari, N. (2019), "Corporate governance and environmental social governance disclosure: A meta-analytical review", Corporate Social Responsibility and Environmental Management, John Wiley \& Sons, Ltd, 1 July.

Li, A., McCauley, K.D. and Shaffer, J.A. (2017), “The influence of leadership behavior on employee work-family outcomes: A review and research agenda", Human Resource Management Review, JAI, Vol. 27 No. 3, pp. 458-472. 
Liao, C., Wayne, S.J. and Rousseau, D.M. (2016), "Idiosyncratic deals in contemporary organizations: A qualitative and meta-analytical review", Journal of Organizational Behavior, John Wiley \& Sons, Ltd, Vol. 37, pp. S9-S29.

Lund, D.S. (2020), "Enlightened Shareholder Value, Stakeholderism, and the Quest for Managerial Accountability", SSRN Electronic Journal, Elsevier BV, available at:https://doi.org/10.2139/SSRN.3725725.

McMullan, A.D., Lapierre, L.M. and Li, Y. (2018), “A qualitative investigation of workfamily-supportive coworker behaviors", Journal of Vocational Behavior, Academic Press, Vol. 107, pp. 25-41.

Norling, L.R. and Chopik, W.J. (2020), "The Association Between Coworker Support and Work-Family Interference: A Test of Work Environment and Burnout as Mediators", Frontiers in Psychology, Frontiers, Vol. 11, p. 819.

Padavic, I., Ely, R.J. and Reid, E.M. (2020), “Explaining the Persistence of Gender Inequality: The Work-family Narrative as a Social Defense against the 24/7 Work Culture*", Administrative Science Quarterly, SAGE Publications Ltd, Vol. 65 No. 1, pp. 61-111.

Parmar, B.L., Freeman, R.E., Harrison, J.S., Wicks, A.C., Purnell, L. and Colle, S. de. (2010), "Stakeholder Theory: The State of the Art", New Pub: Academy of Management, Routledge , Vol. 4 No. 1, pp. 403-445.

Qing, G., Zhang, H. and Wang, Z. (2021), "How and when family-supportive supervisor behaviors foster work engagement and gratitude: A moderated mediation model”, Social Behavior and Personality, Scientific Journal Publishers, Vol. 49 No. 1, available at:https://doi.org/10.2224/SBP.9179.

Qing, G. and Zhou, E. (2017), "Bidirectional work-family enrichment mediates the relationship between family-supportive supervisor behaviors and work engagement", Social Behavior and Personality, Society for Personal Research, Vol. 45 No. 2, pp. 299308.

Rofcanin, Y., Heras, M. Las and Bakker, A.B. (2017), "Family supportive supervisor behaviors and organizational culture: Effects on work engagement and performance", Journal of Occupational Health Psychology, American Psychological Association Inc., Vol. 22 No. 
2, pp. 207-217.

Rofcanin, Y., Heras, M. Las, Bosch, M.J., Berber, A., Mughal, F. and Ozturk, M. (2021), “Servant leadership and family supportiveness: Looking into employees' work and family outcomes", Journal of Business Research, Elsevier, Vol. 128, pp. 70-82.

Rofcanin, Y., de Jong, J.P., Heras, M. Las and Kim, S. (2018), "The moderating role of prosocial motivation on the association between family-supportive supervisor behaviours and employee outcomes", Journal of Vocational Behavior, Academic Press, Vol. 107, pp. $153-167$.

Rothschild, J. (2000), “Creating a just and democratic workplace: More engagement, less hierarchy", Contemporary Sociology, American Sociological Association, Vol. 29 No. 1, pp. 195-213.

Rousseau, D.M., Ho, V.T. and Greenberg, J. (2006), "I-Deals: Idiosyncratic Terms in Employment Relationships", Https://Doi.Org/10.5465/Amr.2006.22527470, Academy of Management Briarcliff Manor, NY 10510, Vol. 31 No. 4, pp. 977-994.

Russo, M., Buonocore, F., Carmeli, A. and Guo, L. (2015), "When Family Supportive Supervisors Meet Employees' Need for Caring: Implications for Work-Family Enrichment and Thriving:", Https://Doi.Org/10.1177/0149206315618013, SAGE PublicationsSage CA: Los Angeles, CA, Vol. 44 No. 4, pp. 1678-1702.

Sirgy, M.J. and Lee, D.-J. (2017), “Work-Life Balance: an Integrative Review”, Applied Research in Quality of Life 2017 13:1, Springer, Vol. 13 No. 1, pp. 229-254.

Vaziri, H., Casper, W.J., Wayne, J.H. and Matthews, R.A. (2020), "Changes to the work-family interface during the COVID-19 pandemic: Examining predictors and implications using latent transition analysis", Journal of Applied Psychology, American Psychological Association, Vol. 105 No. 10, pp. 1073-1087.

Waldman, D., Luque, M.S. de, Washburn, N., House, R.J., Adetoun, B., Barrasa, A., Bobina, M., et al. (2006), "Cultural and leadership predictors of corporate social responsibility values of top management: A GLOBE study of 15 countries", Journal of International Business Studies, Palgrave Macmillan Ltd., Vol. 37 No. 6, pp. 823-837. 
Welch, K., Yoon, A., Edmans, A., Eccles, R., Flammer, C., Gow, I., Hoepnner, J., et al. (2020), "Corporate Sustainability and Stock Returns: Evidence from Employee Buy-in to Senior Management".

Yoon, B., Lee, J.H. and Byun, R. (2018), "Does ESG Performance Enhance Firm Value? Evidence from Korea", Sustainability 2018, Vol. 10, Page 3635, Multidisciplinary Digital Publishing Institute, Vol. 10 No. 10, p. 3635.

Zhang, S. and Tu, Y. (2016), “Cross-Domain Effects of Ethical Leadership on Employee Family and Life Satisfaction: the Moderating Role of Family-Supportive Supervisor Behaviors”, Journal of Business Ethics 2016 152:4, Springer, Vol. 152 No. 4, pp. 10851097. 